\title{
Research and Optimization of Gas Extraction by Crossing-Seam Boreholes from Floor Roadway
}

\author{
Gang Li $(\mathbb{D})$ and Jiafei Teng \\ College of Mining, Liaoning Technical University, Fuxin, Liaoning Province, China \\ Correspondence should be addressed to Gang Li; ligang@lntu.edu.cn
}

Received 3 June 2021; Accepted 25 July 2021; Published 10 August 2021

Academic Editor: Feng Du

Copyright (c) 2021 Gang Li and Jiafei Teng. This is an open access article distributed under the Creative Commons Attribution License, which permits unrestricted use, distribution, and reproduction in any medium, provided the original work is properly cited.

\begin{abstract}
Deep coal seams are characterized by large stress, high gas pressure, and low permeability. The gas disaster threatens the safe production of coal mine seriously. Gas extraction by crossing-seam boreholes from floor roadway (GECMBFR) can reduce the pressure and content of coal seam gas, which is the main measure to prevent gas disaster. Considering the Klinkenberg effect, governing equations of gas adsorption/desorption-diffusion, gas seepage, and stress fields within the coal seam are established to form the seepage-stress coupling model. The governing equations are embodied into a finite element driven software to numerically simulate gas migration and fluid-solid coupling law in coal seam. On this basis, the process of gas extraction under different borehole spacings and diameters is simulated. The effects of these two key parameters on coal seam gas pressure, gas content, and gas permeability were analyzed. The borehole spacing and diameter were determined to be $5 \mathrm{~m}$ and $0.09 \mathrm{~m}$, respectively. Combined with the actual situation of a mine, the process of gas extraction from floor roadway with different cross-sectional schemes, ordinary drilling boreholes and punching combined drilling boreholes, is comparatively analyzed. The results show that the gas extraction effect by ordinary drilling boreholes is lower than that of the punching combined drilling boreholes, and the extraction is uneven and makes it difficult to meet the standard. Hydraulic punching was carried out, and coal was washed out of the borehole, which expanded the contact area between the borehole wall and coal seam. The coal seam around the punching borehole is unloaded, which improves coal permeability and accelerates gas migration towards the borehole, thus promoting the efficiency of gas extraction. It is more reasonable to use punching combined drilling borehole scheme when implementing the GECMBFR technology.
\end{abstract}

\section{Introduction}

As the mining depth increases, gas pressure and content in coal seam increase. This may lead to gas accidents such as coal and gas outburst and gas explosion, which seriously threaten the safety production of coal mine $[1,2]$. Gas extraction by borehole drilling from floor roadway can effectively reduce coal seam gas and eliminate gas disaster risk [3]. Reasonable arrangement parameters of extraction boreholes can avoid blind extraction area among boreholes and improve gas extraction volume. Meanwhile, an optimal scheme will reduce drilling construction and thus decrease the cost of field application. Understanding the law of gas migration in the coal seam is the key to determine the reasonable borehole parameters [4].
Scholars have studied the interaction relationship between coal and gas. They consider that the change of geostress and gas pressure in the coal seam will cause coal deformation and change of porosity and permeability. For instance, Liang et al. [5], Xu et al. [6], and Connell [7] established gas-solid coupling models of coal and gas under different stress conditions. Then, the gas ad/desorption-induced coal deformation is introduced into the gas-solid coupling model [8-10]. In fact, the existence of water in the coal seam will occupy the migration channel of methane and reduce the relative permeability of gas phase $[11,12]$. At the same time, the gas flow in the coal seam is very different from the liquid flow, because the effective permeability depends on the compressibility and gas pressure [13]. The dependence of coal seam permeability on gas pressure is called the Klinkenberg 
effect. It has important influence on gas flow behavior [14]. In previous studies, the Klinkenberg effect is often ignored, resulting in large errors in borehole design and gas extraction calculation $[15,16]$.

In this study, considering the action of the Klinkenberg effect, the seepage-stress coupling model for gas extraction from coal seam is established by combining the controlling equations of gas diffusion field in coal matrix, gas seepage field in fractures, and stress field within the coal seam. The mathematical equations were embedded into the finite element (FE) analysis software to model the gas extraction through boreholes from floor roadway. The influence of borehole spacing and borehole diameter on gas extraction through boreholes is analyzed. And the research results provide guidance for optimizing the borehole schedule of gas extraction.

\section{Seepage-Stress Coupling Model for Coal Seam Gas Extraction}

Considering the occurrence environment of coal seam gas, we put forward the following assumptions [17-19]: (1) coal seam is an elastic continuous medium, which contains both fractures and porous matrix; (2) gas adsorbs on the surface of both pores and fractures, and gas transports in the space of pores and fractures in the state of free; (3) with the process of gas extraction, gas first desorbs from the surface of pores and then diffuses into fractures and finally seepages into boreholes from the fractures, obeying the Langmuir adsorption law, Fick's law, and Darcy's law, respectively; and (4) gas is a kind of ideal gas.

2.1. Controlling Equation of Seepage Field. Coal seam is structured by pores, fractures, and solid phase. Coal seam gas is generated from the solid phase and stored within the pores and fractures. In the coal matrix, gas content includes adsorbed and free gas. The gas content in the coal matrix can be expressed as [20]

$$
m_{\mathrm{m}}=V_{\mathrm{sg}} \rho_{\mathrm{s}} \rho_{\mathrm{gs}}+\varphi_{\mathrm{m}} \rho_{\mathrm{mg}}
$$

where $V_{\text {sg }}$ is volume of adsorbed coalbed methane, $\mathrm{m}^{3} / \mathrm{kg} ; \rho_{\mathrm{s}}$ is density of coal skeleton, $\mathrm{kg} / \mathrm{m}^{3} ; \rho_{\mathrm{gs}}$ is gas density in standard state, $\mathrm{kg} / \mathrm{m}^{3} ; \varphi_{\mathrm{m}}$ is the porosity of the coal matrix; and $\rho_{\mathrm{mg}}$ is gas density in the coal matrix, $\mathrm{kg} / \mathrm{m}^{3}$.

Gas existing in the space of pores and fractures obeys the ideal gas law. The density of free gas is given as

$$
\rho_{\mathrm{g}}=\frac{M_{\mathrm{g}}}{R T} p
$$

where $M_{\mathrm{g}}$ is molar mass of gas, $\mathrm{kg} / \mathrm{mol} ; R$ is molar constant of gas, $\mathrm{J} /(\mathrm{mol} \cdot \mathrm{K})$; $T$ is geothermal temperature, $\mathrm{K}$; and $\mathrm{p}$ is gas pressure, $\mathrm{MPa}$.
The volume of adsorbed coalbed methane in coal matrix can be defined by Langmuir law [10]:

$$
V_{\mathrm{sg}}=\frac{V_{\mathrm{L}} p_{\mathrm{m}}}{P_{\mathrm{L}}+p_{\mathrm{m}}}
$$

where $V_{\mathrm{L}}$ and $P_{\mathrm{L}}$ are the Langmuir constants and $p_{\mathrm{m}}$ is gas pressure in matrix, $\mathrm{Pa}$.

Before the operation of gas extraction, the coal seam gas is in the state of equilibrium, namely, gas pressure in pores equals that of gas in fractures. After implementing gas extraction, the equilibrium is disturbed, and the gas desorbs from the surface of pores and diffuses into the fractures driven by concentration gradient. By using Fick's law, the mass conservation in the porous matrix is obtained [13]:

$$
\frac{\partial m_{\mathrm{m}}}{\partial t}=-\frac{M_{\mathrm{g}}}{\tau R T}\left(p_{\mathrm{m}}-p_{\mathrm{f}}\right)
$$

where $p_{\mathrm{f}}$ is gas pressure in coal fracture, $\mathrm{MPa}$, and $\tau$ is diffusion time, $s$.

Combining Equations (1)-(4), the controlling equation of gas migration in the matrix is gained:

$$
\frac{\partial}{\partial t}\left(\frac{V_{\mathrm{L}} p_{\mathrm{m}}}{P_{\mathrm{L}}+p_{\mathrm{m}}} \rho_{\mathrm{s}} \frac{M_{\mathrm{g}}}{R T_{\mathrm{s}}} p_{\mathrm{s}}+\varphi_{\mathrm{m}} \frac{M_{\mathrm{g}}}{R T} p_{\mathrm{m}}\right)=-\frac{M_{\mathrm{g}}}{\tau R T}\left(p_{\mathrm{m}}-p_{\mathrm{f}}\right) .
$$

For gas transporting in a fracture system, the diffused gas from the coal matrix acts as the mass source, and the gas mass conservation of the fracture system can be expressed as [21]

$$
\frac{\partial\left(\varphi_{f} \rho_{\mathrm{g}}\right)}{\partial t}+\nabla \cdot\left(\rho_{\mathrm{g}} \vec{q}_{\mathrm{g}}\right)=\left(1-\varphi_{\mathrm{f}}\right) \frac{M_{\mathrm{g}}}{\tau R T}\left(p_{\mathrm{m}}-p_{\mathrm{f}}\right)
$$

where $\varphi_{\mathrm{f}}$ is porosity of fracture and $\vec{q}_{\mathrm{g}}$ is seepage velocity of gas, $\mathrm{m} / \mathrm{s}$.

The Klinkenberg effect will increase the apparent permeability especially when the gas pressure is low. Considering this, we define the gas flow rate in the fracture as $[21,22]$

$$
\vec{q}_{\mathrm{g}}=-\frac{k}{\mu_{\mathrm{g}}}\left(1+\frac{b_{\mathrm{k}}}{p_{\mathrm{f}}}\right) \nabla p_{\mathrm{f}}
$$

where $k$ is fracture permeability, $\mathrm{m}^{2} ; \mu_{\mathrm{g}}$ is gas dynamic viscosity, $\mathrm{Pa} \cdot \mathrm{s}$; and $b_{\mathrm{k}}$ is slippage factor, $\mathrm{Pa}$.

Submitting Equation (7) into (6), the controlling equation of seepage field of gas can be obtained:

$$
\frac{\partial}{\partial t}\left(\varphi_{\mathrm{f}} \frac{M_{\mathrm{g}}}{R T} p_{f}\right)+\nabla \cdot\left(-\frac{M_{\mathrm{g}}\left(p_{\mathrm{f}}+b_{\mathrm{k}}\right)}{R T} \frac{k}{\mu_{\mathrm{g}}} \nabla p_{\mathrm{f}}\right)=\left(1-\varphi_{\mathrm{f}}\right) \frac{M_{\mathrm{g}}}{\tau R T}\left(p_{\mathrm{m}}-p_{\mathrm{f}}\right) .
$$




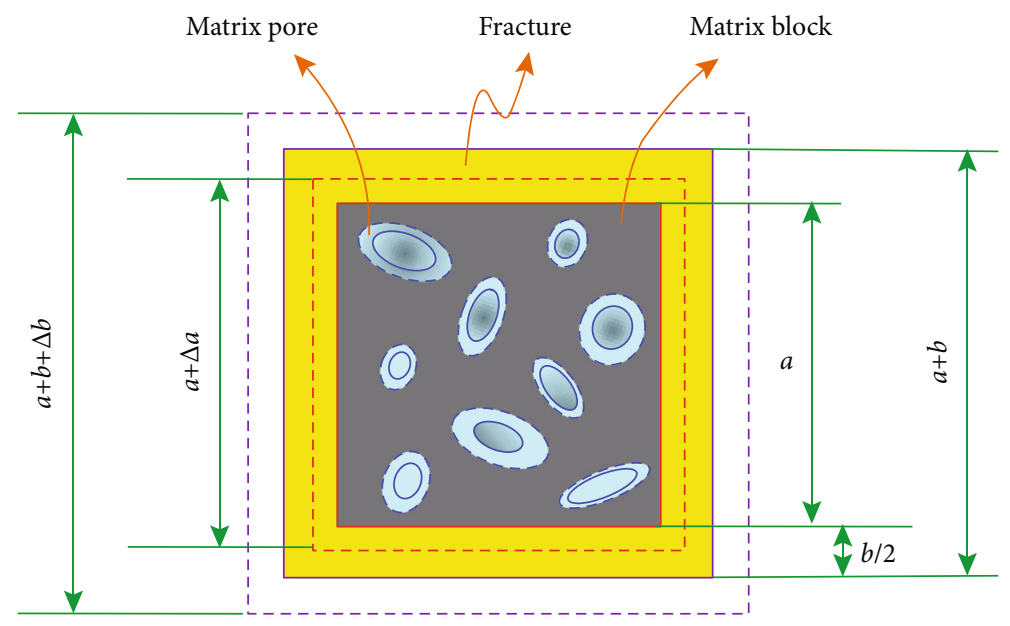

Figure 1: Conceptual model of representational element volume of coal mass.

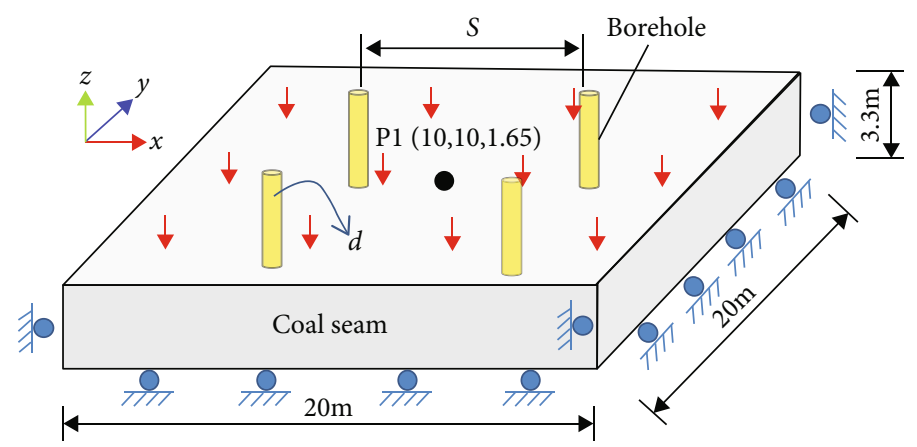

FIGURE 2: Geometric model for investigating the influence of borehole parameters on gas extraction.

2.2. Controlling Equation of Stress Field. The strain of coal mass is the sum of strain caused by stress, gas pressure, gas ad/desorption, and temperature change [20]:

$$
\varepsilon_{i j}=\frac{1}{2 G} \sigma_{i j}-\left(\frac{1}{6 G}-\frac{1}{9 K}\right) \sigma_{k k} \delta_{i j}+\frac{\alpha_{\mathrm{m}} p_{\mathrm{m}}+\alpha_{\mathrm{f}} p_{\mathrm{f}}}{3 K} \delta_{i j}+\frac{\varepsilon_{\mathrm{a}}}{3} \delta_{i j}
$$

where $\delta_{i j}$ is Kronecker sign; $D$ is modified elastic modulus, GPa; $D=1 /\left(1 / E_{\mathrm{s}}+1 /\left(a K_{n}\right)\right) ; G$ is shear modulus of coal, $\mathrm{GPa} ; G=D / 2(1+v) ; K$ is volume modulus of coal, GPa, $K$ $=D / 3(1-2 v) ; K_{\mathrm{s}}$ is volume modulus of coal skeleton, $\mathrm{GPa}$; $K_{n}$ is the stiffness of fracture, GPa; $v$ is the Poisson ratio; $\alpha_{\mathrm{m}}$ and $\alpha_{\mathrm{f}}$ are effective stress coefficients; $a$ is the length of matrix, $\mathrm{m} ; \varepsilon_{\mathrm{a}}$ is gas adsorption-caused strain of coal skeleton, which is proportional to adsorption capacity [13]:

$$
\varepsilon_{\mathrm{a}}=\alpha_{\mathrm{sg}} V_{\mathrm{sg}}
$$

where $\alpha_{\mathrm{sg}}$ is strain coefficient of gas adsorption, $\mathrm{kg} / \mathrm{m}^{3}$.
According to the classical mechanics, the straindisplacement equation and static equilibrium of coal seam can be derived as

$$
\left\{\begin{array}{l}
\varepsilon_{i j}=\frac{1}{2}\left(u_{i, j}+u_{j, i}\right), \\
\sigma_{i j, j}+F_{i}=0,
\end{array}\right.
$$

where $F$ is volume force, $\mathrm{Pa}$; $u$ is the displacement, $\mathrm{m}$; and the subscript $i$ and $j$ stand for the direction of $x, y$, and $z$.

Combining Equations (9)-(11), the controlling equation of stress field can be obtained:

$$
G u_{i, j j}+\frac{G}{1-2 v} u_{j, j i}-\alpha_{\mathrm{m}} p_{\mathrm{m}, i}-\alpha_{f} p_{f, i}-K \varepsilon_{\mathrm{a}, i}+F_{i}=0
$$

2.3. Porosity and Permeability Equations. The mechanical properties of coal seam are largely dependent on the structure of pores and fractures. Porosity and permeability are the key parameters for evaluating gas migration in coal. The variation of pores and fractures is closely related to the stress state, as well as the mechanical properties of coal seam. 
TABLE 1: Relevant parameters for simulation of gas extraction.

\begin{tabular}{|c|c|c|c|}
\hline Parameter name & Value & Parameter name & Value \\
\hline Initial gas pressure of coal seam $\left(p_{0}, \mathrm{MPa}\right)$ & 1.0 & Geothermal temperature $\left(T_{0}, \mathrm{~K}\right)$ & 300 \\
\hline Gas adsorption volume constant $\left(V_{L}, \mathrm{~m}^{3} / \mathrm{kg}\right)$ & 0.0256 & Adsorption strain coefficient $\left(\varepsilon_{\max }, \mathrm{kg} / \mathrm{m}^{3}\right)$ & 0.06 \\
\hline Gas adsorption pressure constant $\left(P_{L}, \mathrm{MPa}\right)$ & 1.07 & Molar mass of gas $\left(M_{g}, \mathrm{~g} / \mathrm{Mol}\right)$ & 16 \\
\hline Gas dynamic viscosity $\left(\mu_{g}, \mathrm{~Pa} \cdot \mathrm{s}\right)$ & $1.84 \times 10^{-5}$ & Molar gas constant $(R, \mathrm{~J} /(\mathrm{Mol} \cdot \mathrm{K})$ & 8.314 \\
\hline Hydrodynamic viscosity $\left(\mu_{w}, \mathrm{~Pa} \cdot \mathrm{s}\right)$ & $1.03 \times 10^{-3}$ & Standard temperature $\left(T_{s}, \mathrm{~K}\right)$ & 273.5 \\
\hline Gas desorption time $(\tau, \mathrm{d})$ & 1.21 & Standard atmospheric pressure $\left(p_{s}, \mathrm{kPa}\right)$ & 101 \\
\hline Initial porosity of coal $\left(\varphi_{m 0}\right)$ & 0.035 & Coal density $\left(\rho_{c}, \mathrm{~kg} / \mathrm{m}^{3}\right)$ & 1410 \\
\hline Initial fracture degree of coal $\left(\varphi_{f 0}\right)$ & 0.012 & Initial permeability $\left(k_{f 0}, \mathrm{~m}^{2}\right)$ & $1.8 \times 10^{-17}$ \\
\hline Slippage factor $\left(b_{k}, \mathrm{MPa}\right)$ & 0.36 & Poisson's ratio of coal $(v)$ & 0.35 \\
\hline
\end{tabular}

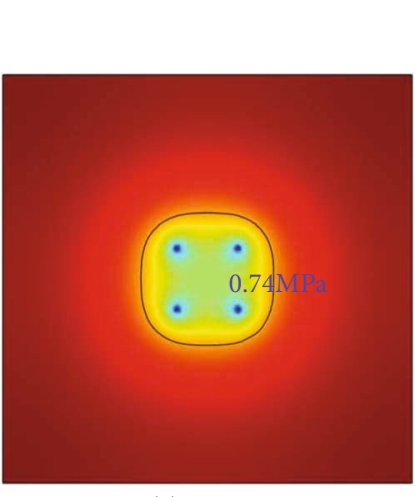

(a) $S=3 \mathrm{~m}$

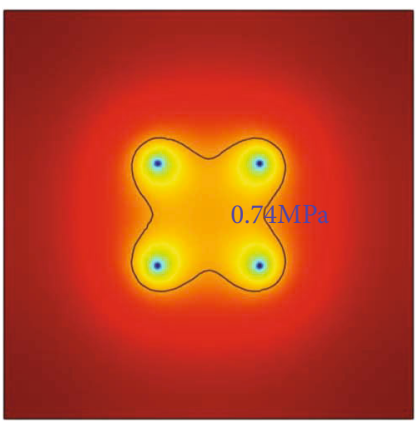

(c) $S=5 \mathrm{~m}$

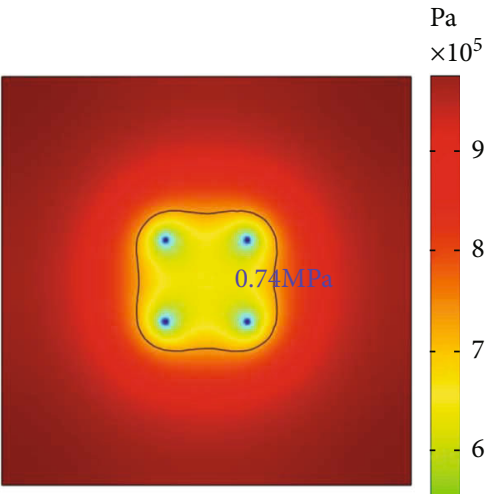

(b) $S=4 \mathrm{~m}$

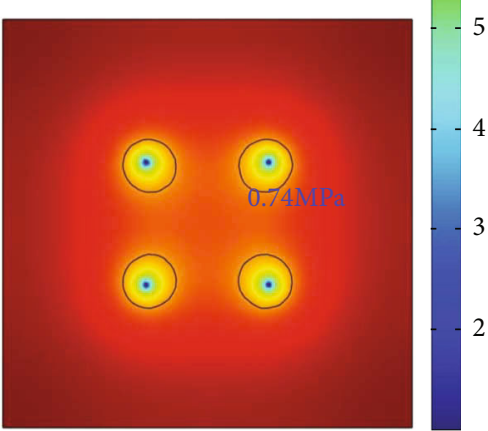

(d) $S=6 \mathrm{~m}$

Figure 3: Gas pressure with different borehole spacings after 120 days' extraction.

The equation of matrix porosity is taken from a published literature, which is defined as [23]

$$
\varphi_{\mathrm{m}}=\frac{\varphi_{\mathrm{m} 0}\left(1+S_{0}\right)+\alpha_{\mathrm{m}}\left(S-S_{0}\right)}{(1+S)},
$$

in which the strain $S=\varepsilon_{\mathrm{v}}+p_{\mathrm{m}} / K_{\mathrm{s}}-\varepsilon_{\mathrm{a}} ; \varepsilon_{\mathrm{v}}$ is the volume strain of coal; and the subscript " 0 " stands for the initial state.

The conceptual model of presentational element volume (REV) in the coal seam is shown in Figure 1, where $a$ is defined as the length of the matrix and $b$ is the length of the fracture.
Fracture porosity is taken as [24]

$$
\phi_{\mathrm{f}}=\phi_{\mathrm{f} 0}+\frac{\phi_{\mathrm{f} 0} K_{\mathrm{m}}}{3\left(K_{\mathrm{f}}+K_{\mathrm{m}} / r_{\mathrm{mt}}^{3}-K_{\mathrm{m}}\right)}\left(\Delta \varepsilon_{\mathrm{a}}+\frac{\Delta \varepsilon_{\mathrm{v}}}{r_{\mathrm{mt}}^{3}}+\frac{\alpha_{\mathrm{m}} \Delta p_{\mathrm{m}}}{K_{\mathrm{m}}}\right),
$$

where $K_{\mathrm{f}}$ is improving fracture stiffness, $K_{\mathrm{f}}=b K_{n}$, GPa; $r_{\mathrm{m}}=a /(a+b)$ is defined as the proportion of matrix length to the REV length; and $K_{\mathrm{m}}$ is the bulk modulus of the matrix, $\mathrm{Pa}$. 


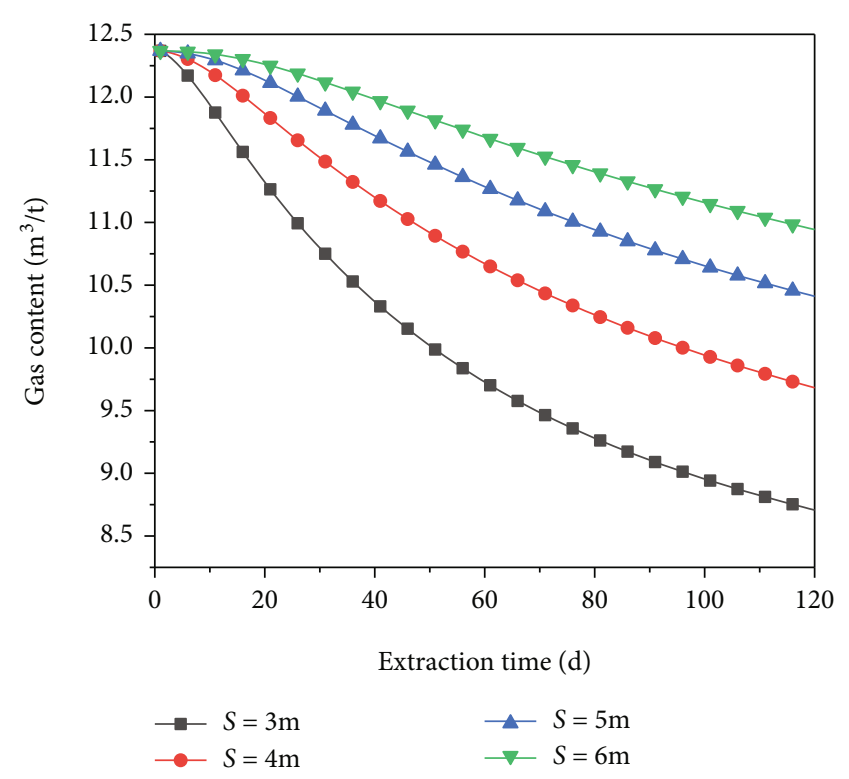

FIGURE 4: Gas content in the coal seam with different borehole spacings.

The cubic law is adopted to illustrate the relation of fracture permeability and fracture porosity [25], which is expressed as

$$
\frac{k}{k_{0}}=\left(\frac{\varphi_{\mathrm{f}}}{\varphi_{\mathrm{f} 0}}\right)^{3}
$$

Submitting Equation (14) into Equation (15), the available fracture permeability is

$k=k_{0}\left(1+\frac{K_{\mathrm{m}}}{3\left(K_{\mathrm{f}}+K_{\mathrm{m}} / r_{\mathrm{mt}}^{3}-K_{\mathrm{m}}\right)}\left(\Delta \varepsilon_{\mathrm{a}}+\frac{\Delta \varepsilon_{\mathrm{v}}}{r_{\mathrm{mt}}^{3}}+\frac{\alpha_{\mathrm{m}} \Delta p_{\mathrm{m}}}{K_{\mathrm{m}}}\right)\right)^{3}$,

where $k_{0}$ is initial permeability, $\mathrm{m}^{2}$.

By using the partial differential equations of Equations (5), (8), and (12)-(16), the seepage-stress coupling model is obtained, and the partial differential equations can be embedded into software by programming to simulate the law of gas extraction by drilling through floor roadway.

\section{Effects of Borehole Spacing and Diameter on Gas Extraction through Boreholes}

3.1. Geometric Model and Definite Solution Condition. In order to design and optimize the layout scheme of gas extraction through boreholes in floor extraction roadway, the influence of borehole spacing and borehole diameter on gas extraction through boreholes was studied. The threedimensional geometric model of gas extraction through boreholes in floor roadway is constructed, as shown in Figure 2. Coal seam is a cuboid with a size of $20 \mathrm{~m} \times$ $20 \mathrm{~m} \times 3.3 \mathrm{~m}$. The four borehole centers are square and

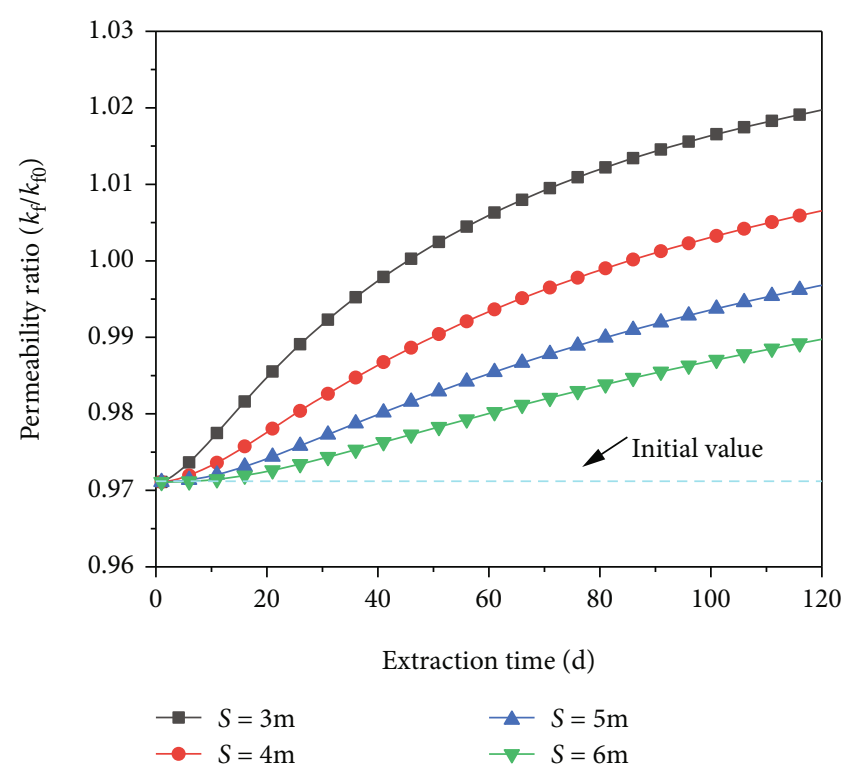

Figure 5: Coal permeability with different borehole spacings.

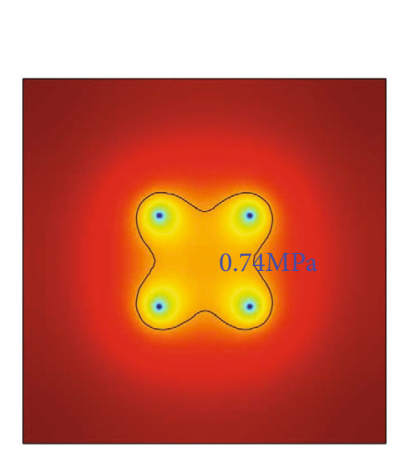

(a) $d=0.09 \mathrm{~m}$

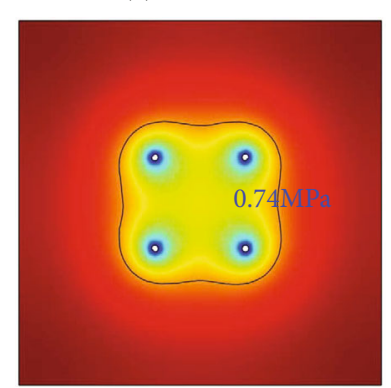

(c) $d=0.37 \mathrm{~m}$

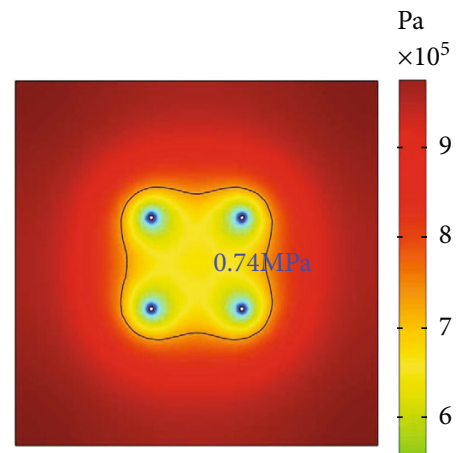

(b) $d=0.23 \mathrm{~m}$

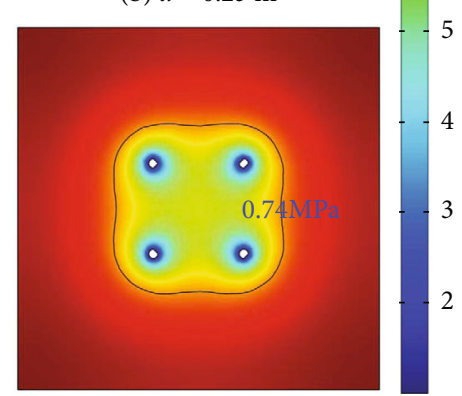

(d) $d=0.51 \mathrm{~m}$
FIgURE 6: Gas pressure in the coal seam with different borehole diameters.

arranged in the center of the model. The borehole spacing is $S$, while the borehole diameter is $d$.

When solving the mathematical model, the sliding boundary is around the geometric model in Figure 2. The bottom is fixed boundary, and the top is applied with $15 \mathrm{MPa}$ of vertical stress. The extern sides of the model are set as impermeable boundaries, indicating that there are no gas flows at these boundaries. The borehole wall of the extraction borehole is set as the pressure boundary condition, 


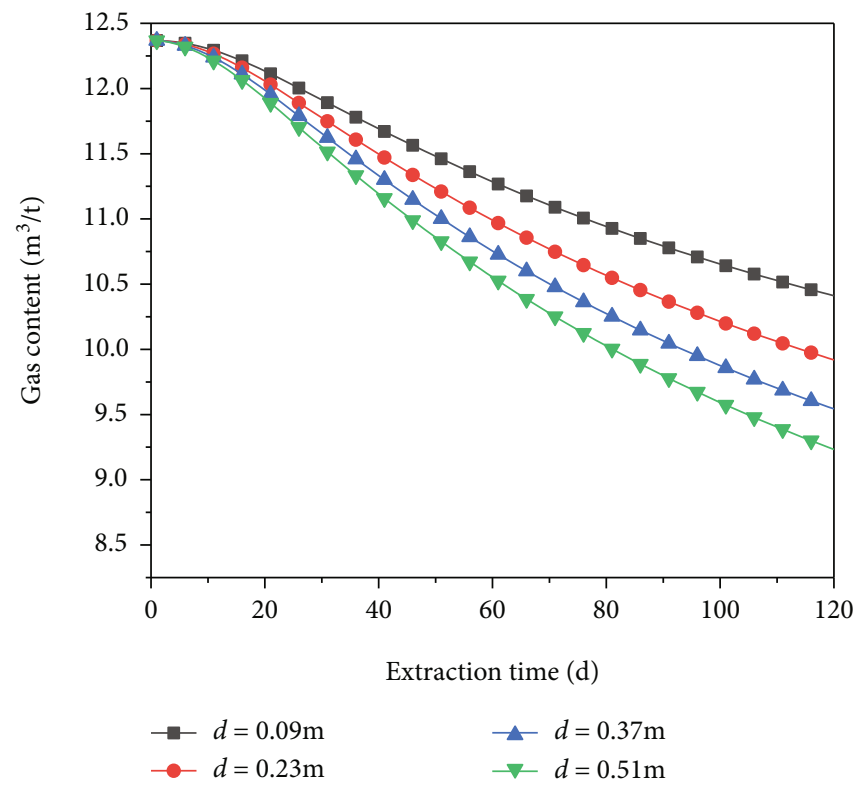

FIGURE 7: Gas content in the coal seam with different borehole diameters.

and the extraction pressure is $20 \mathrm{kPa}$. For the simulation of gas extraction by crossing-seam boreholes, the initial gas pressure is $1.0 \mathrm{MPa}$, and the initial permeability is $1.8 \times 10^{-17} \mathrm{~m}^{2}$. Other relevant parameters are shown in Table 1 .

In order to facilitate the analysis, the single variable control method is used. On the basis of keeping other parameters unchanged, the gas extraction law of borehole spacing or diameter in the range of change is discussed. In other words, when the borehole spacing is studied, the borehole diameter is fixed to $0.09 \mathrm{~m}$, and the borehole spacing is set to $3 \mathrm{~m}$, $4 \mathrm{~m}, 5 \mathrm{~m}$, and $6 \mathrm{~m}$, respectively. To reveal the influencing law of varying borehole diameters on the gas extraction efficiency, we set four sizes of borehole diameter starting from $0.09 \mathrm{~m}$ with an interval of $0.14 \mathrm{~m}$. When the borehole diameter is research objectives, the borehole spacing is fixed to $5 \mathrm{~m}$, and the borehole diameter is set to $0.09 \mathrm{~m}, 0.23 \mathrm{~m}$, $0.37 \mathrm{~m}$, and $0.51 \mathrm{~m}$, respectively.

3.2. Effect of Borehole Spacing on Gas Extraction by CrossingSeam Boreholes. After 120 days' gas extraction, the contour of gas pressure with a borehole spacing of $3 \mathrm{~m}, 4 \mathrm{~m}, 5 \mathrm{~m}$, and $6 \mathrm{~m}$ is shown in Figure 3.

The black line represents the gas pressure $0.74 \mathrm{MPa}$. When the gas pressure is lower than $0.74 \mathrm{MPa}$, it meets requirements of gas extraction. Under the action of extraction pressure, coal seam gas migrates into the borehole, and the gas pressure near the borehole decreases. With the operation of extraction, the area of gas pressure reduction extends outward. After 120 days' extraction, the volume of effective gas extraction for a borehole spacing of $3 \mathrm{~m}, 4 \mathrm{~m}, 5 \mathrm{~m}$, and $6 \mathrm{~m}$ is $119.75,143.65,152.69$, and $69.43 \mathrm{~m}^{3}$, respectively. It is visible; the borehole spacing is not the greater the better, nor the smaller the better. When the borehole spacing is $5 \mathrm{~m}$, the effective gas extraction area is the largest and the efficiency of gas extraction is the highest.
Under different borehole spacings, the variation of gas content with time at reference point P1 is shown in Figure 4. With the prolonging of gas extraction, the gas content at the reference point gradually decreases. In the same time interval, the decline of gas content at the initial stage is greater than that at the late stage of extraction. The greater the borehole spacing, the smaller the degree of gas content reduction. Meanwhile, the decrease of gas content is nonlinear with the increase of borehole spacing. For example, at 60 days of extraction, the gas content at the reference point P1 with $3,4,5$, and $6 \mathrm{~m}$ borehole spacing is $9.73,10.67,11.29$, and $11.68 \mathrm{~m}^{3} / \mathrm{t}$, respectively, which is $21.29 \%, 13.66 \%, 8.69 \%$, and $5.49 \%$ lower than that of the original gas content. After 120 days' extraction, the gas content is $8.71,9.68,10.41$, and $10.94 \mathrm{~m}^{3} / \mathrm{t}$, respectively, which is $29.55 \%, 21.66 \%, 15.76 \%$, and $11.46 \%$ lower than the original gas content, respectively.

Under different borehole spacings, the variation of coal seam permeability with time at position $\mathrm{P} 1$ of reference point is shown in Figure 5. From the Equation (16), the actual permeability of coal seam is the result of the competition of permeability in free stress state and the coaction of gas pressure, ground stress, and adsorption deformation. The permeability ratio of coal seam at the reference point P1 at the initial stage of extraction is 0.9713 . With the increase of extraction time, the permeability of the reference point position increases gradually. The larger the borehole spacing is, the smaller the increase of permeability is, and the two are nonlinear. After 120 days of extraction, the permeability ratios of coal seams were $1.0197,1.0065,0.997$, and 0.9897 , respectively, which were $5.01 \%, 3.66 \%, 2.65 \%$, and $1.93 \%$ higher than the original permeability, respectively.

3.3. Effect of Borehole Diameter on Gas Drainage by Crosslayer Boreholes. When gas extraction is conducted for 120 days, the gas pressure distribution in the coal seam with a borehole diameter of $0.09 \mathrm{~m}, 0.23 \mathrm{~m}, 0.37 \mathrm{~m}$, and $0.51 \mathrm{~m}$ is 


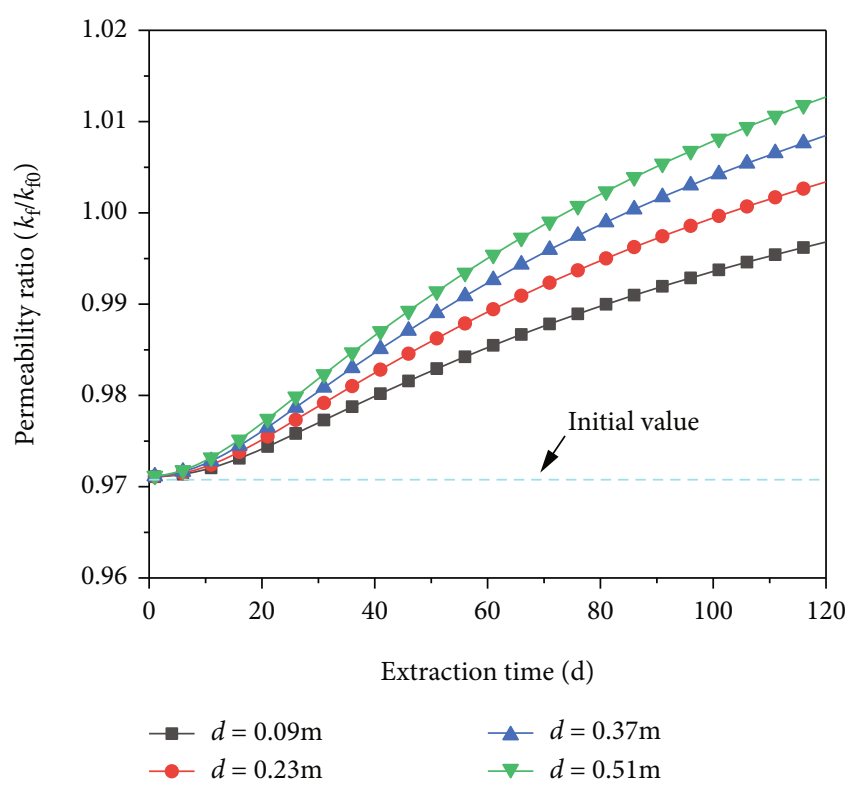

FIgURE 8: Coal permeability with different borehole diameters.

presented in Figure 6. The gas pressure of $0.74 \mathrm{MPa}$ in the coal seam is considered as the requirement of effective gas extraction. The increase of borehole diameter expands the contact area between borehole wall and coal seam, and the area of gas pressure reduction increases. After 120 days of extraction, the effective gas extraction volumes with borehole diameters of $0.09 \mathrm{~m}, 0.23 \mathrm{~m}, 0.37 \mathrm{~m}$, and $0.51 \mathrm{~m}$ were $152.69 \mathrm{~m}^{3}, 208.49 \mathrm{~m}^{3}, 240.18 \mathrm{~m}^{3}$, and $263.78 \mathrm{~m}^{3}$, respectively. The effective gas extraction volume of $0.51 \mathrm{~m}$ borehole diameter increased by $111.09 \mathrm{~m}^{3}$ compared with $0.09 \mathrm{~m}$ borehole diameter, which increased by $72.75 \%$. When the borehole diameter is $0.09 \mathrm{~m}$, the effective extraction area of the four boreholes has been connected into pieces to meet the extraction requirements.

Gas content at reference point P1 with the different borehole diameters of $0.09 \mathrm{~m}, 0.23 \mathrm{~m}, 0.37 \mathrm{~m}$, and $0.51 \mathrm{~m}$ varies, as shown in Figure 7 . The greater the diameter is, the smaller the residual gas content is. After 120 days' extraction, the gas content of reference point $\mathrm{P} 1$ with borehole diameters of $0.09 \mathrm{~m}, 0.23 \mathrm{~m}, 0.37 \mathrm{~m}$, and $0.51 \mathrm{~m}$ were $10.41 \mathrm{~m}^{3} / \mathrm{t}$, $9.92 \mathrm{~m}^{3} / \mathrm{t}, 9.54 \mathrm{~m}^{3} / \mathrm{t}$, and $9.23 \mathrm{~m}^{3} / \mathrm{t}$, respectively, which were $3.298 \mathrm{~m}^{3} / \mathrm{t}, 3.791 \mathrm{~m}^{3} / \mathrm{t}, 4.166 \mathrm{~m}^{3} / \mathrm{t}$, and $4.477 \mathrm{~m}^{3} / \mathrm{t}$ lower than those of initial gas content $-13.71 \mathrm{~m}^{3} / \mathrm{t}$. It can be found that the borehole diameter of $0.51 \mathrm{~m}$ is 4.67 times larger than that of $0.09 \mathrm{~m}$, while the decrease amplitude of gas content only increases by 0.36 times. Therefore, gas content cannot be reduced multiply when the borehole diameter multiplied. The decrease of gas content is the comprehensive effect of permeability, gas pressure gradient, and borehole diameter.

Figure 8 shows the permeability variation in the coal seam with time at reference point $\mathrm{P} 1$ under different borehole diameters. With the development of gas extraction, the permeability of the reference point position increases gradually, which is mainly controlled by the shrinkage of coal matrix. The greater the borehole diameter is, the higher the increment of permeability is, and both of them are nonlinear. After 120 days' extraction, coal permeabilities were

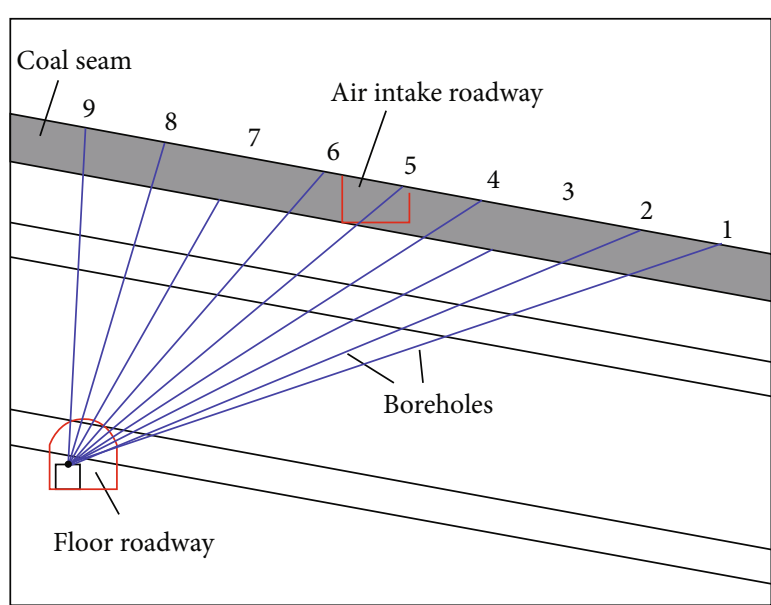

FIGURE 9: Section of gas extraction boreholes drilling from floor roadway.

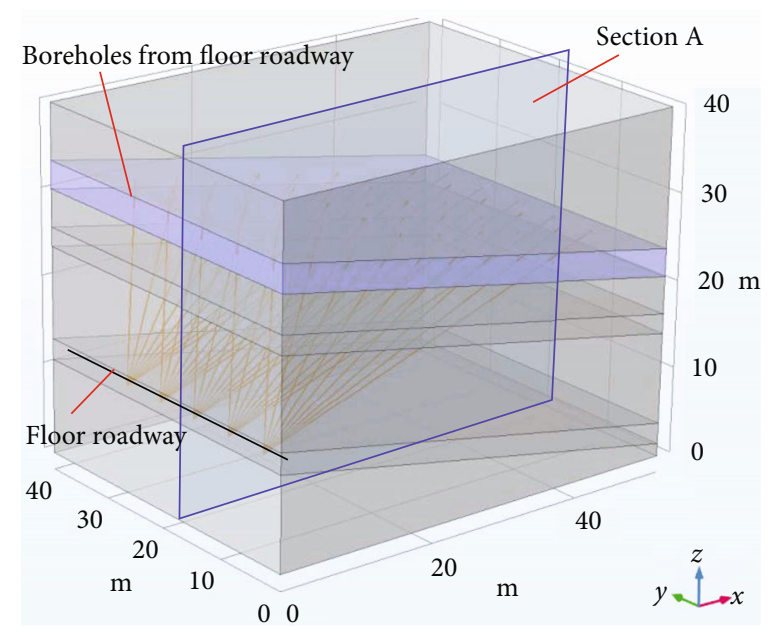

Figure 10: Geometric model of gas extraction boreholes drilling from floor roadway.

$0.9968,1.0034,1.0085$, and 1.0127 , respectively, which were $2.65 \%, 3.33 \%, 3.86 \%$, and $4.95 \%$ higher than the original permeability, respectively.

\section{Scheme Optimization of Gas Extraction by Crossing-Seam Boreholes from Floor Roadway}

The length of the mine field in a coal mine is about $4 \mathrm{~km}$ north and south, and the width of the east and west is about $3 \mathrm{~km}$. The mine field area is $12.87 \mathrm{~km}^{2}$, and the approved production capacity is 1.4 million $\mathrm{t} / \mathrm{a}$. The dynamic phenomena of coal and gas outburst occurred 28 times in total. The types of gas outburst were mainly pressure, outburst, and dumping. The maximum outburst gas amount was $25704 \mathrm{~m}^{3}$, and the maximum outburst coal amount was $293 \mathrm{t}$. With the depletion of shallow coal resources, coal mining gradually shifts to the deep. The coal seam shows complex occurrence conditions, high geostress, high gas, and low permeability, and the outburst risk increases. 


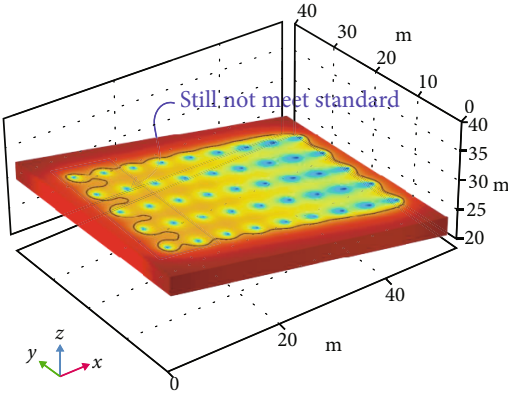

(a) Drilling boreholes

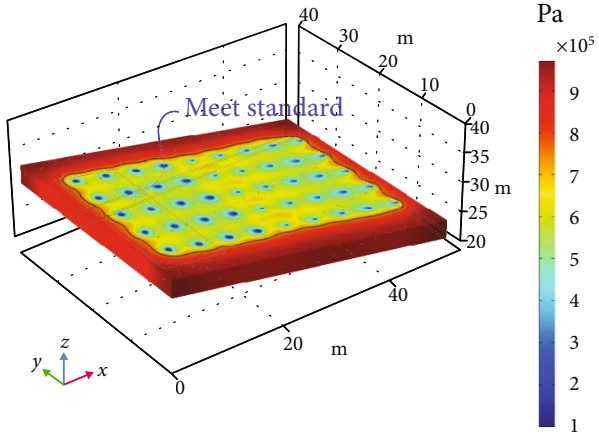

(b) Drilling and punching boreholes

Figure 11: Gas pressure in the coal seam after 120 days' extraction.

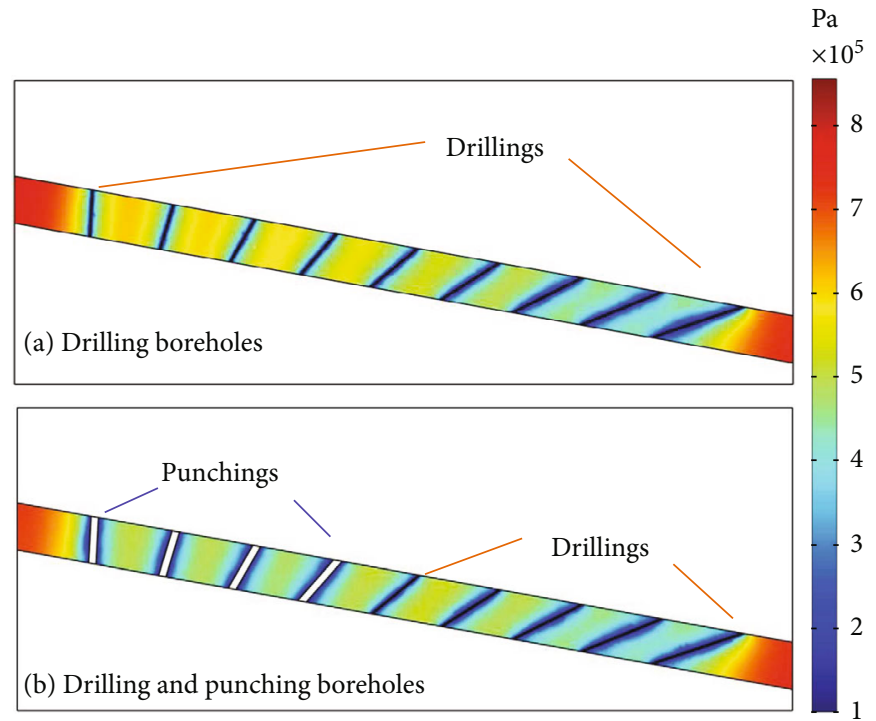

Figure 12: Gas pressure distribution on section A under two extraction schemes.

The construction was carried out at $20 \mathrm{~m}$ outside the floor gas extraction roadway of intake roadway, and the interval between the two roadway layers was $18 \mathrm{~m}$. Starting at $35 \mathrm{~m}$ from the floor roadway opening, a group of boreholes were designed for each $6 \mathrm{~m}$, with 9 boreholes in each group, and the aperture was $89 \mathrm{~mm}$. The borehole control range is $15 \mathrm{~m}$ outside the contour line of the two sides of the intake roadway. The depth of the borehole is $0.5 \mathrm{~m}$ above the roof of the 15 coal seam. Figure 9 is the plane layout of the gas extraction borehole in the floor roadway. In addition, in order to compare and analyze and optimize the scheme, the pore size of $6 \# \sim 9$ \# borehole is expanded to $500 \mathrm{~mm}$ by hydraulic punching in Figure 9; that is, $1 \# \sim 5$ \# is ordinary extraction borehole and $6 \# \sim 9$ \# is hydraulic punching.

According to the gas extraction scheme of intake roadway, a three-dimensional geometric model of numerical calculation is established (Figure 10). Reference section A is set in the geometric model to observe the change of gas pressure in the coal seam.

Figure 11 shows the gas pressure distribution nephogram of the two extraction schemes after 120 days of extraction. In
Figure 11(a), the gas pressure drops faster in coal seams far from the floor extraction roadway and slower in coal seams near the floor extraction roadway. After 120 days of extraction, there are still substandard extraction areas that do not meet the requirement of less than $0.74 \mathrm{MPa}$ near the floor extraction roadway. By comparison, it is found that the gas pressure in the coal seam near or far from the floor extraction roadway in Figure 11(b) decreases rapidly. This is due to the hydraulic punching of four boreholes close to the floor roadway, which expands the borehole diameter. The extraction effect of hydraulic punching is obviously better than that of ordinary drilling. The main reasons may include the following: (1) hydraulic punching flushes the coal out of the borehole, expanding the contact area between the borehole wall and the coal seam; (2) after the coal is washed out, the coal around the hydraulic punching is unloaded. The permeability of coal seam is improved, the speed of gas migration to borehole is accelerated, and the efficiency of gas extraction is promoted.

As illustrated in Figure 12, the gas pressure of coal seam on section A is extracted. Figure 12(a) shows the results of 
cross section using a crosslayer drilling scheme, and Figure 12(b) shows the results of gas extraction using five crosslayer drilling and four hydraulic punching. In the case of scheme 1, that is, through-layer drilling scheme is adopted for all sections. The gas pressure decreases significantly in the area far from the floor extraction roadway, while the gas pressure decreases slightly in the area near the floor extraction roadway. The reason is that the inclination angle of the borehole far from the floor extraction roadway is small, the trajectory through the coal seam is longer, and the contact area formed with the coal seam is larger. Under the same negative pressure of extraction, the extraction effect is better. In the case of scheme 2, the hydraulic punching is used near the floor extraction roadway, and the ordinary drilling is used far from the floor extraction roadway. In the area where the hydraulic punching is arranged, the gas pressure decreases rapidly, and the extraction reaches the standard after 120 days. In the case of scheme 2, namely, hydraulic punching is adopted near the floor pumping roadway on the cross section. The scheme of ordinary drilling is adopted far from the floor extraction roadway. In the area where hydraulic punching is arranged, the gas pressure drops rapidly, and the extraction can reach the extraction standard after 120 days of extraction. In summary, using the extraction scheme of full-section ordinary crosslayer drilling, the extraction effect on the side near the floor extraction roadway is lower than that on the side far from the floor extraction roadway due to the short trajectory of crosslayer drilling through the coal seam, which leads to uneven extraction and difficulty in reaching the standard. The gas efficiency will be greatly improved by further hydraulic punching on the basis of the borehole near the floor extraction roadway, expanding the borehole diameter and increasing the exposed area of the borehole coal wall. At the same time, hydraulic punching is not required for all boreholes, which saves the construction cost. Therefore, it is more reasonable to adopt the scheme of common through-layer drilling and hydraulic punching.

\section{Conclusions}

(1) The controlling equations of gas adsorption/desorption-diffusion field in coal matrix, gas seepage field, and stress field in coal fracture are derived on the basis of assuming coal seam as pore-fracture dualporosity medium. Combined with the coupling terms such as porosity and permeability, the seepage-stress coupling model of gas migration considering the Klinkenberg effect is established, which can be used to study the law of coal seam gas extraction

(2) The gas extraction law of a four-hole model in horizontal coal seam was simulated, and the influence of borehole spacing and diameter on gas pressure, gas content, and coal permeability after different extraction times was analyzed. Under the simulated coal seam conditions, the effective extraction area increases first and then decreases with the borehole spacing. And the borehole spacing of $5 \mathrm{~m}$ is more reasonable. The effective extraction area increases with the increase of borehole spacing. Under the conditions permitted, increasing the borehole diameter will significantly improve the efficiency of gas extraction

(3) The gas extraction process of floor roadway crossing layer under the full-section ordinary drilling scheme and the hydraulic punching combined with ordinary drilling scheme was compared and analyzed. Adopting hydraulic punching near floor extraction roadway, enlarging borehole diameter, and increasing exposure area of borehole wall will greatly improve gas efficiency. It is more reasonable to adopt the scheme of common crossing-seam drilling combined with hydraulic punching boreholes

Coal seam is characterized by heterogenous properties, while the change of coal seam temperature will have an impact on the results. Therefore, the heterogeneity of coal seam and the thermal effect will be considered in the future works.

\section{Data Availability}

The data used in this article were from the simulation results by COMSOL Multiphysics. The equations were written as COMSOL codes independently to conduct these simulations. The data are available from the corresponding author upon request.

\section{Conflicts of Interest}

The authors declare no competing financial interest.

\section{Acknowledgments}

This research was financially supported by the National Natural Science Foundation of China (Grant No. 51774165) and the project of discipline innovation team of Liaoning Technical University (Grant No. LNTU20TD-05).

\section{References}

[1] I. Palmer, "Coalbed methane completions: a world view," International Journal of Coal Geology, vol. 82, no. 3-4, pp. 184-195, 2010.

[2] C. Fan, S. Li, D. Elsworth, J. Han, and Z. Yang, "Experimental investigation on dynamic strength and energy dissipation characteristics of gas outburst-prone coal," Energy Science \& Engineering, vol. 8, no. 4, pp. 1015-1028, 2020.

[3] W. He, F. He, K. Zhang, Y. Zhao, and H. Zhu, "Increasing permeability of coal seam and improving gas drainage using a liquid carbon dioxide phase transition explosive technology," Advances in Civil Engineering, vol. 2018, Article ID 3976505, 15 pages, 2018.

[4] C. Fan, S. Li, M. Luo, W. Du, and Z. Yang, "Coal and gas outburst dynamic system," International Journal of Mining Science and Technology, vol. 27, no. 1, pp. 49-55, 2017.

[5] B. Liang, M. Zhang, and Y. Wang, "Mathematical model and numerical method for coupled gas flow in coal seams and coal deformation," Chinese Journal of Rock Mechanics and Engineering, vol. 15, no. 2, pp. 40-47, 1996. 
[6] T. Xu, C. Tang, L. Song, T. Yang, and Z. Liang, "Numerical simulation of coupled gas flow in failure process of gassy coal-rock," Chinese Journal of Rock Mechanics and Engineering, vol. 24, no. 10, pp. 1667-1673, 2005.

[7] L. Connell, "Coupled flow and geomechanical processes during gas production from coal seams," International Journal of Coal Geology, vol. 79, no. 1-2, pp. 18-28, 2009.

[8] P. Guo, S. G. Cao, Z. G. Zhang, Y. Li, Y. B. Liu, and Y. Li, "Analysis of solid gas coupling model and simulation of coal containing gas," Journal of China Coal Society, vol. 37, no. 1, pp. 330-335, 2012.

[9] G. Yin, M. Li, S. Li, W. Li, J. Yao, and Q. Zhang, "3D numerical simulation of gas drainage from boreholes based on solid gas coupling model of coal containing gas," Journal of China Coal Society, vol. 38, no. 4, pp. 535-541, 2013.

[10] T. Xia, F. Zhou, J. Liu, and F. Gao, "Evaluation of the predrained coal seam gas quality," Fuel, vol. 130, pp. 296-305, 2014.

[11] S. Chen, Study on Coupled Deformation and Gas-Water Two Phase Flow Model for Fractured Coal and Rock, Northeastern University, Shenyang, 2012, (thesis).

[12] W. Zhao, K. Wang, R. Zhang, H. Dong, Z. Lou, and F. An, "Influence of combination forms of intact sub-layer and tectonically deformed sub-layer of coal on the gas drainage performance of boreholes: a numerical study," International Journal of Coal Science \& Technology, vol. 7, no. 3, pp. 571$580,2020$.

[13] W. Zhu, J. Liu, J. Sheng, and D. Elsworth, "Analysis of coupled gas flow and deformation process with desorption and Klinkenberg effects in coal seams," International Journal of Rock Mechanics and Mining Sciences, vol. 44, no. 7, pp. 971-980, 2007.

[14] G. Hu, H. Wang, X. Fan, Z. Yuan, and S. Hong, "Mathematical model of coalbed gas flow with Klinkenberg effects in multiphysical fields and its analytic solution," Transport in Porous Media, vol. 76, no. 3, pp. 407-420, 2009.

[15] C. Fan, D. Elsworth, S. Li, L. Zhou, Z. Yang, and Y. Song, "Thermo-hydro-mechanical-chemical couplings controlling $\mathrm{CH}_{4}$ production and $\mathrm{CO}_{2}$ sequestration in enhanced coalbed methane recovery," Energy, vol. 173, pp. 1054-1077, 2019.

[16] T. Liu, B. Lin, X. Fu, Y. Zhao, Y. Gao, and W. Yang, "Modeling coupled gas flow and geomechanics process in stimulated coal seam by hydraulic flushing," International Journal of Rock Mechanics and Mining Sciences, vol. 142, article 104769, 2021.

[17] J. Liu, L. Xie, D. Elsworth, and Q. Gan, “CO2/CH4 competitive adsorption in shale: implications for enhancement in gas production and reduction in carbon emissions," Environmental science \& technology, vol. 53, no. 15, pp. 9328-9336, 2019.

[18] J. Liu, L. Xie, Y. Yao, Q. Gan, P. Zhao, and L. Du, "Preliminary study of influence factors and estimation model of the enhanced gas recovery stimulated by carbon dioxide utilization in shale," ACS Sustainable Chemistry \& Engineering, vol. 7, no. 24, pp. 20114-20125, 2019.

[19] Q. Huang, S. Liu, W. Cheng, and G. Wang, "Fracture permeability damage and recovery behaviors with fracturing fluid treatment of coal: an experimental study," Fuel, vol. 282, article 118809, 2020.

[20] C. Fan, D. Elsworth, S. Li et al., "Modelling and optimization of enhanced coalbed methane recovery using $\mathrm{CO}_{2} / \mathrm{N}_{2}$ mixtures," Fuel, vol. 253, pp. 1114-1129, 2019.
[21] P. Thararoop, Z. Karpyn, and T. Ertekin, "Development of a multi-mechanistic, dual-porosity, dual-permeability, numerical flow model for coalbed methane reservoirs," Journal of Natural Gas Science and Engineering, vol. 8, no. 9, pp. 121131, 2012.

[22] C. Wu, C. Yuan, G. Wen, L. Han, and H. Liu, "A dynamic evaluation technique for assessing gas output from coal seams during commingling production within a coalbed methane well: a case study from the Qinshui Basin," International Journal of Coal Science \& Technology, vol. 7, no. 1, pp. 122-132, 2020.

[23] Y. Wu, J. Liu, D. Elsworth, X. Miao, and X. Mao, "Development of anisotropic permeability during coalbed methane production," Journal of Natural Gas Science and Engineering, vol. 2, no. 4, pp. 197-210, 2010.

[24] C. Fan, S. Li, H. Zhang, and Z. Yang, "Rational boreholes arrangement of gas extraction from unloaded coal seam," Advances in Civil Engineering, vol. 2018, 9 pages, 2018.

[25] S. Li, C. J. Fan, J. Han, M. K. Luo, Z. H. Yang, and H. J. Bi, “A fully coupled thermal-hydraulic-mechanical model with twophase flow for coalbed methane extraction," Journal of Natural Gas Science and Engineering, vol. 33, pp. 324-336, 2016. 